\title{
Object shift and subject shift
}

\author{
Hans Broekhuis
}

Received: 23 May 2004 / Accepted: 04 September 2005/Published online: 10 July 2007

(C) Springer Science+ Business Media B.V. 2007

\begin{abstract}
Adopting the hypothesis that both NP-movement of subjects and scrambling of objects are instances of A-movement, this article aims at accounting for the similarities and differences between these movements within the so-called derivation-and-evaluation framework, which combines certain aspects from the minimalist program and optimality theory.
\end{abstract}

Keywords A-scrambling $\cdot$ A $^{\prime}$-scrambling $\cdot$ Derivation-and-evaluation model $\cdot$ Minimalist program $\cdot$ NP-movement $\cdot$ Object shift $\cdot$ Optimality theory $\cdot$ Subject shift

\section{Introduction}

This article is concerned with comparing scrambling of objects and NP-movement of the subject, and aims at accounting for the similarities and differences between these movement types within the derivation-and-evaluation (D\&E) framework developed in Broekhuis and Dekkers (2000) and subsequent work. Before I present this framework in Sect. 2, I will first briefly introduce the topic of discussion, starting with the notion of object scrambling.

The existing approaches to object scrambling can be divided into three different groups depending on the question whether it is considered to be A- or $\mathrm{A}^{\prime}$-movement or to involve base-generation; a representative sample of these approaches can be found in Corver and Van Riemsdijk (1994). Webelhuth $(1989,1992)$ has shown that Dutch/German object scrambling has properties of

H. Broekhuis $(\bowtie)$

Leiden University, Leiden University Center for Linguistics (LUCL),

P.O. box 9500, 2300 RA Leiden, The Netherlands

e-mail: Hans.Broekhuis@let.leidenuniv.nl 
both $\mathrm{A}$ - and $\mathrm{A}^{\prime}$-movement, a fact that is often referred to as Webelhuth's paradox. For example, the fact that scrambling feeds binding is a typical A-movement property (cf. Vanden Wyngaerd 1988, 1989), whereas the fact that scrambling licenses parasitic gaps is generally considered an $\mathrm{A}^{\prime}$-movement property (cf. Bennis and Hoekstra 1984; see De Hoop and Kosmeijer 1991 and Broekhuis 1992, however, for some problems for this claim). The binding facts are illustrated in (1); note that example (1a) slightly improves if the adverbial phrase namens elkaar 'on behalf of each other' is assigned contrastive accent, which might be due to the fact that (1a) might then be derived from (1b) by means of (reconstructable) focus movement (see below example (2)). The parasitic gap facts are illustrated in (2).

(1) a. *Hij heeft namens
he has on.behalf.of each.other the boys visited
b. Hij heeft de jongens $\mathrm{i}_{\mathrm{i}}$ namens elkaar
he has the boys $t_{\mathrm{i}}$ bezocht.
'He visited the boys on behalf of each other.'

(2) a. *Hij heeft [zonder PROpg te bekijken] het boek opgeborgen.
he has without

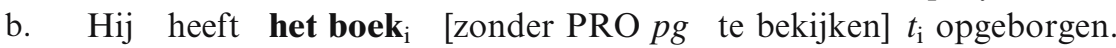
he has the book without to look-at prt-filed

'He filed the book without looking (at it).

The, to my mind, most plausible solution to Webelhuth's paradox is to assume that the notion of scrambling is not a unitary phenomenon, but actually refers to (at least) two different phenomena (cf. Vanden Wyngaerd 1988, 1989; Déprez 1989; Mahajan 1990; Neeleman 1994a), which one might refer to as object shift and focus/negation movement, respectively. The fact that the object in (3) is able to both bind the anaphor and to license the parasitic gap can then be accounted for as follows: binding of the anaphor elkaar 'each other' is made possible by object shift, that is, by the intermediate trace $t^{\prime}$, which occupies an A-position; the parasitic gap is licensed by focus movement, that is, by the DP preceding the adjunct clause, which presumably occupies the specifier position of a FocusP.

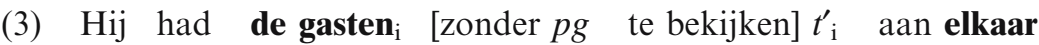
he had the guests without to look.at to each.other $t_{\mathrm{i}}$ voorgesteld. introduced

'He had introduced the guests to each other without looking (at them).'

An important difference between object shift and focus/negation movement is that the former can be applied to nominal objects only, whereas the latter can be applied to a wider range of constituents; see Sect. 4 for some discussion. One reason for using the name 'object shift' for the A-movement 
type of scrambling is that Scandinavian object shift is also restricted to nominal objects. The two processes further exhibit a number of similarities which suggests that they should receive a uniform analysis (see, among others, Vikner 1990, 1994; Zwart 1997; Broekhuis 1999, 2000 for discussion).

Broekhuis $(1999,2000)$ has argued that Dutch object shift can be described in an optimality-theoretic fashion by assuming the constraint ranking in (4). The constraints AGREEMENT and CASE require that the uninterpretable agreement and case features, which I assume to be situated on, respectively, $\mathrm{V}$ and $v$, trigger movement of the object into the minimal domains of $\mathrm{V}$ and $v$. The fact that these two constraints outrank STAY means that, in the normal case, these movements take effect. The constraint ALIGNFOCUs requires that the prosodically unmarked focus be as close as possible to the right edge of its clause (cf. Costa 1998), and it is the interaction of this constraint with CASE that is responsible for scrambling.

Dutch: AGREEMENT $\gg$ ALIGNFOCUS $\gg$ CASE $\gg$ STAY

In order to avoid confusion it is important to note that the notion of prosodically unmarked focus refers to the new information of the clause and stands in opposition to the notion of presupposition, the old information of the clause. The notion of prosodically unmarked focus must certainly not be confused with the notion of exhaustive or contrastive focus, which is always marked by means of a marked accent and may trigger the earlier mentioned focus movement into SpecFocusP.

Now, consider the structure in (5). Following Kayne's (1994) universal base hypothesis, according to which all languages have an underlying specifier-headcomplement order, the position $\mathrm{OBJ}_{1}$ in this structure is the base position of the object. Position $\mathrm{OBJ}_{2}$ is the specifier position associated with the agreement features on $\mathrm{V}$. The partial ranking AGREEMENT $\gg$ ALIGNFOCUS $\gg$ STAY expresses that movement into this position is obligatory, irrespectively of the question whether the object is part of the focus of the clause or not: given that V-to- $v$ does not apply in Dutch embedded clauses, this entails that Dutch is an OV-language. ${ }^{1}$ Position $\mathrm{OBJ}_{3}$ is the specifier position associated with the case features of $v$. The partial ranking ALIGNFOCUS $>$ CASE $\gg$ STAY expresses that movement into this position is blocked when the object belongs to the focus of the clause, but obligatory in other cases, that is, that scrambling is sensitive to

\footnotetext{
${ }^{1}$ The assumption that the agreement features are not situated on $v$, but on $\mathrm{V}$ is now also adopted in Chomsky (2005) in the guise of his theory of feature inheritance. This assumption can be used to settle the long standing debate initiated in Johnson (1991) and Koizumi (1993) on the question whether English has object shift or not. For example, the fact that subjects of infinitival clauses can bind anaphors embedded in adjuncts of the main clause (e.g., Lasnik 1999) and the antecedent contained deletion phenomena (e.g., Hornstein 1995) strongly suggest that object shift does apply in English. When object shift is triggered by $\mathrm{AGR}_{\mathrm{O}} / v$, however, this leads to wrong predictions about English word order: under the standard assumption that English main verbs do not move to I (e.g., Emonds 1985; Pollock 1989; and Chomsky 1991), object shift triggered by $\mathrm{AGR}_{\mathrm{O}} / v$ would give rise to an $\mathrm{OV}$-order. Assuming that the agreement features on $\mathrm{V}$ may also trigger object shift solves this problem, provided that this movement is subsequently made invisible by V-to- $v$. See Broekhuis (in prep.) for a detailed discussion and more evidence in favor of movement of the object in English.
} 
the information structure of the clause. See Broekhuis $(1999,2000)$ for a more extensive discussion and technical details.

$$
\left[\mathrm{OBJ}_{3} \ldots v\left[\mathrm{OBJ}_{2} \ldots \mathrm{V} \mathrm{OBJ}_{1}\right]\right.
$$

Finally, note that focus movement (scrambling of the $\mathrm{A}^{\prime}$-movement type) targets SpecFocusP, a position structurally higher than $\mathrm{OBJ}_{3}$. This position is the landing site of an exhaustively focused constituent, which may but need not be the object.

Now that I have clarified the notions of scrambling and object shift, we may continue with the relation between object shift and NP-movement of the subject. Since the constraints AGREEMENT and CASE simply require that the $\Phi$ - and case features trigger movement of their goal, they do not distinguish between subjects and objects. Consequently, the prediction is that the conditions under which subjects and objects are moved are similar: agreement on the finite verb should obligatorily trigger movement of the subject, whereas the case features should do so only when the subject is part of the presupposition of the clause.

In many cases object shift and NP-movement in Dutch/German indeed seem to be subject to similar constraints (cf. Diesing 1992; De Hoop 1992, and many others). Sect. 3.1 will show that the subject exhibits the behavior that is expected on the basis of the partial ranking ALIGNFOCUS $\gg$ CASE $\gg$ STAY. In order to stress this similarity in behavior between NP-movement and object shift, I will henceforth refer to the former process as subject shift. A potential problem is that the subject does not exhibit the behavior that is expected on the basis of the partial ranking AGREEMENT $>$ ALIGNFOCUS $\gg$ STAY. Sect. 3.2 will argue, however, that this is not a problem for the present approach, but follows from the nature of the agreement relations the object and the subject enter into.

The analysis in Sect. 3 adopts as its point of departure Vanden Wyngaerd's (1988, 1989) claim that object shift is A-movement, which can therefore apply to NPs only. Some studies (Haeberli 2002, being the most recent one) have claimed, however, that scrambling of complement PPs exhibits similar properties as scrambling of objects. Section 4 contests this claim, and argues that scrambling of PPs is actually movement of the $\mathrm{A}^{\prime}$-movement type, probably into the specifier of a FocusP. The conclusions reached in sect. 3 also give rise to some speculations on what I will call 'short' object shift, that is, scrambling of the object into a position following the sentence adverbs. Sect. 5 concludes with a brief discussion of this type of movement.

\section{The derivation-and-evaluation framework}

This section briefly discuses the main aspects of the D\&E framework and places the discussions in Sects. 3-5 in their wider context. This section will further update the D\&E framework by taking into consideration some recent developments in the minimalist program. 


\subsection{The D\&E model}

The framework assumed in this paper is the derivation-and-evaluation (D\&E) model developed in Broekhuis and Dekkers (2000) and Broekhuis (1999, 2000). In its original formulation, the D\&E model takes an adapted version of Chomsky's (1995b) computational system of human language $\left(\mathrm{C}_{\mathrm{HL}}\right)$ as a generator, which produces candidate sets that are evaluated in an optimalitytheoretic manner.

The Derivation-and-Evaluation Model (Broekhuis and Dekkers, 2000; Broekhuis, 2000)

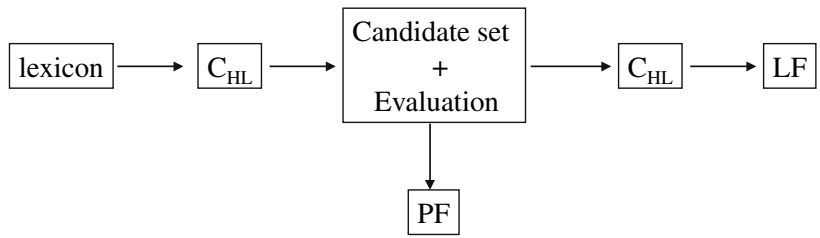

Just as in the minimalist program (MP), the computational system $\mathrm{C}_{\mathrm{HL}}$ is assumed to be universal and to consist of operations that are conceptually necessary, such as MERGE, MOVE/ATTRACT and DELETE. The D\&E model therefore differs from 'standard' OT in that it assumes a highly structured generator, the operations of which are furthermore subject to inviolable conditions: any application of MOVE/ATTRACT, for example, must satisfy Last Resort and the Minimal Link Condition, that is, the condition in (7), taken from Chomsky (1995b, p. 297), holds in full force.

$\mathrm{K}$ attracts $\mathrm{F}$ iff $\mathrm{F}$ is the closest feature that can enter into a checking relation with a sublabel of $\mathrm{K}$.

The net result is that each candidate set contains a limited number of candidates only, namely those that satisfy the inviolable condition in (7) on MOVE/ATTRACT, and other such constraints on the operations MERGE and DELETE.

The main difference with the 'standard' versions of $\mathrm{MP}$ is that $\mathrm{C}_{\mathrm{HL}}$ is not parameterized: there are no strength/EPP-features that may force or block the application of a certain operation. Neither can an operation be blocked by the availability of a more economical option. ${ }^{2}$ At any point $\mathrm{P}$ in the derivation, $\mathrm{C}_{\mathrm{HL}}$ may choose at random between applying or not applying the operation(s) that could in principle be performed at $\mathrm{P} ; \mathrm{C}_{\mathrm{HL}}$ thus defines a candidate set, which can be seen as a family of derivations. The candidate sets defined by $\mathrm{C}_{\mathrm{HL}}$ can be assumed to be very similar for all languages: variation in candidate sets is

\footnotetext{
${ }^{2}$ Cf. Broekhuis and Klooster (2001) who argue that Merge is not universally preferred to Move: assuming that Merge is costless simply gives rise to the wrong empirical predictions. The fact that Merge seems to come for free in English is due to the fact that Move is generally not a favored option in this language, that is, that STAY is ranked fairly high and outranks * MERGE $(=$ do not merge): STAY $\gg *$ MERGE. For Dutch the ranking is arguably the inverse: *MERgE $\gg$ STAY.
} 
possibly limited to differences resulting from the lexicon, such as the availability of certain lexical items and the affixal/non-affixal status or categorial nature of the lexical elements involved in the derivation.

Of course, the effects of the strength/EPP-features must be mimicked in some way. In order to obtain this let us first generalize the basic effect of these features by assuming that all probes ( $=$ uninterpretable/unvalued formal features) prefer movement of their goal $(=$ an element containing a feature that may check/value the probe) into their local domain. This can be done by postulating the constraint family EPP (F) in (8): if the goal of probe $\mathrm{F}$ is an XP, (8) forces it to move into a specifier of the head associated with F. More specific instantiations of the generalized EPP are the constraints CASE and AGREEMENT mentioned in the introduction, which require movement of a DP into the minimal domain of a head containing case or $\Phi$-features.

(i) CASE: a case-feature attracts its goal.

(ii) AGREEMENT: $\Phi$-features attract their goal.

(iii) etc.

Word order variation between languages can now be accounted for by assuming that the constraints that make up EPP (F) interact in an optimalitytheoretic fashion with other constraints in the universal set of violable constraints CON. Instead of assuming that strength/EPP-features are associated with a subset of the uninterpretable formal features, it is now assumed that some constraints belonging to EPP (F) are ranked higher than the economy constraint STAY, whereas others are ranked lower. Under the 'strong' ranking of EPP (F) in (9b), movement of the goal of F is forced by EPP (F), whereas under the 'weak' ranking of $\mathrm{F}$ in (9a), movement is blocked by STAY.

(9) a. weak ranking: STAY $\gg \operatorname{EPP}(\mathrm{F})$

b. strong ranking: $\operatorname{EPP}(\mathrm{F}) \gg$ STAY

The main advantage of this formalization of feature strength is that even under the 'weak' ranking movement can be forced provided that there is some higher ranked constraint A that favors this movement (cf. (10a)), and that even under the 'strong' ranking movement can be blocked provided there is some higher ranked constraint B that disfavors it (cf. (10b)).

\footnotetext{
a. A $\gg$ STAY $\gg \operatorname{EPP}(\mathrm{F})$ (if A favors movement, 'Procrastinate' is overruled)

b. B > EPP(F) $\gg$ STAY (if B disfavors movement, 'Strength' is overruled)
} 
Note in this connection that in the early phase of the minimalist program, overriding Procrastinate and feature strength was assumed to be impossible. Chomsky's $(2001$, p. 31), on the other hand, enables us to obtain these effects by postulating a set of language-specific filters on the output of $\mathrm{C}_{\mathrm{HL}}$, which he calls the interpretative component Int. Whereas Int seems to be an alien element within the minimalist program, the proposal in (10) is simply an application of the more general optimality-theoretic methodology.

That overriding of Procrastinate and feature strength is possible was amply illustrated in Broekhuis (1999, 2000). The case depicted in (10a), for example, occurs in Swedish where object shift normally does not occur due to the 'weak' ranking STAY \ CASE. Definite pronouns, on the other hand, do undergo object shift because STAY is outranked by a constraint that prohibits definite pronouns in VP-internal position. The case in (10b) occurs in Icelandic where the 'strong' ranking CASE $\gg$ STAY normally forces object shift. The constraint ALIGNFOCUS, however, outranks CASE with the result that DPs that belong to the focus of the clause do not shift (cf. the discussion of the Dutch ranking in (4), where we actually see the same ranking).

The D\&E model in (6) is modeled after the MP version in Chomsky (1995b): the main idea is that the optimality-theoretic evaluation uniquely determines the Spell-Out point for each language, and that the computation continues covertly after the evaluation in order to eliminate the yet-unchecked features. This assumption is, however, on strained terms with the conclusion reached by Broekhuis and Dekkers (2000) that the candidates in a single candidate set must have the same meaning, where 'meaning' includes notions concerning information structure (as originally proposed by Grimshaw 1997). ${ }^{3}$ All information needed for LF is therefore present at the point of evaluation, and the assumption of post-evaluation application of $\mathrm{C}_{\mathrm{HL}}$, that is, covert movement is only needed for theory-internal reasons, viz., the satisfaction of Full Interpretation. Elimination of covert movement is therefore desirable. This can readily be obtained by adopting the operation Agree (checking at a distance) introduced in the Minimalist Inquiry framework (Chomsky 2000, 2001). Adopting Agree is fully compatible with the idea that the constraint family EPP (F) in (8) is the generalized D\&E counterpart of Chomsky's EPP-feature, that is, it requires that heads with an uninterpretable formal feature $\mathrm{F}$ have a specifier. As a result, we can simply say that the evaluation determines the optimal input for the semantic and the phonological component, so that we can adopt the simplified D\&E model in (11).

\footnotetext{
${ }^{3}$ Broekhuis and Klooster (2001) show that it is not the numeration that determines the candidate set: in fact, they show that the assumption that a derivation takes a numeration as its input is empirically wrong. The notion of enumeration should therefore be eliminated. If so, the assumption that candidate sets are defined in terms of meaning seems to be the only logical possibility left that is consistent with the data, since we would not like an example such as I will read you a poem tomorrow to be blocked by the derivationally simpler form I will read you a poem.
} 
(11)

The Derivation-and-Evaluation Model (updated version)

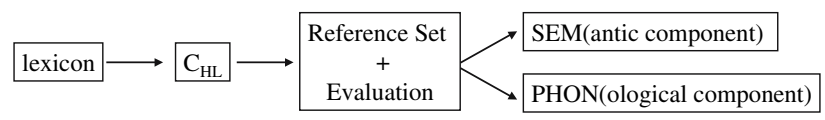

Assuming Agree is of course not the only way of arriving at the model in (11). Dekkers (1999, pp. 33ff), for example, proposes that at the point of evaluation all uninterpretable features are checked as a result of feature movement. The question whether feature movement is reflected in the phonetic output depends on the ranking of the PARSE constraints, which require that movement of the formal features pied pipe the phonological features, and STAY, which in effect blocks pied piping. Since the proposal in Broekhuis (1999, 2000) crucially assumes that certain movements do not apply overtly, I cannot adopt Dekker's proposal (unless one would be willing to assume that the locality constraints do not apply to feature movement). For the same reason, it is also impossible to adopt some version of Groat and O'Neil's (1996) proposal that the difference between 'overt' and 'covert' movement is simply whether the head or the foot of the movement chain is spelled out (cf. Molnárfi 2003, for an application of this proposal to scrambling). A further complication with such a proposal is that additional mechanisms are needed to account for the fact illustrated in (1) that 'overt' and 'covert' movement differ in that only the former feeds binding of anaphors and pronouns (cf. Bobaljik 2002, for a proposal to this effect; see Lee and Santorini 1994; Broekhuis 1994 for more German and Dutch data). Adopting Agree avoids such problems, and by assuming that Agree differs from Move in not being sensitive to the Minimal Link Condition (cf. Chomsky 2001), the results in Broekhuis $(1999,2000)$ can be maintained.

\subsection{D\&E compared to MP and OT}

The model in (11) can be interpreted such that the postulated constraints and their rankings constitute an explicit hypothesis about the interface/bare output conditions, which to a large extent still await explicit formulation in MP. What we have in D\&E is of course still unpretentious but at least the general format that the interface conditions should take is clear. ${ }^{4}$ The assumption that the constraints are part of the definition of the interface conditions also drastically reduces the type of constraints that one would expect. Apart from general economy constraints like STAY, the constraints should bear directly on the three components $\mathrm{C}_{\mathrm{HL}}, \mathrm{SEM}$, and $\mathrm{PHON}$ in (11). This gives rise to the general typology of constraints in (12); the specific constraints mentioned in (12) will be discussed in some detail later in this subsection.

\footnotetext{
${ }^{4}$ Chomsky (2001, ex. (61)) attempts to formulate one of these interface conditions in terms of the interpretative complex Int and Int'. However, this proposal does not provide a general format for the interface conditions, which is also clear from the fact that the crucial part of the proposal, clause (61c), is in effect a language-specific statement (which is acknowledged by Chomsky by calling it a parameter distinguishing object shift from non-object shift languages).
} 
(12) Typology of constraints

a. Economy constraints, e.g., STAY

b. $\mathrm{C}_{\mathrm{HL}}$ constraints, e.g., the constraint family EPP (F)

c. Interface (SEM/PHON) constraints, e.g., ALIGNFOCUS, TEL, LE(CP)

Although the model in (11) comes even closer to the standard OT-framework than that in (6), the discussion above should make it clear that the proposal is more cognate to MP than to the bulk of work in OT-syntax (or OT-phonology for that matter). A quick survey in OT reveals that there is no real meta-theory on constraints: there are few or no explicit restrictions concerning the kind, the number, or the complexity of constraints (the proposal in Eisner, 1999 being a notable exception). D\&E, on the other hand, shares with MP the desire to keep the technical apparatus as small as possible. The requirement that the (syntactic) constraints be related to economy or to the interfaces is a desirable step in the direction of defining the notion of 'possible constraint'. A further restriction that is adopted in D\&E is given in (13).

(13) The constraints should be formulated as simple positive or negative generic statements (cf. Eisner's 1999, implication and clash families) that do not make use of connectives like and, or, unless, etc.

I have the impression that the net result is that the technical apparatus of D\&E, despite its inclusion of an optimality-theoretic evaluator, has about the same degree of complexity as that of the 'standard' version of MP. A full comparison is not possible, of course, because the empirical domains covered by the two proposals do not fully coincide. But to make a start I will show that, insofar as the two can be compared, the technical apparatus of D\&E does not exceed that of MP.

The computational system $\mathrm{C}_{\mathrm{HL}}$ is more or less the same in the two systems, at least in the sense that it involves the same operations: Merge, Agree, Move, and Delete. Also, the (inviolable) conditions on these operations can be assumed to be the same. The computational system of D\&E is simpler in that it is not sensitive to strength/EPPfeatures or economy conditions like "Merge is cheaper than Move". These complicating factors have not been eliminated, however, but simply reappear in the form of constraints and their ranking. In order to compare the degrees of complexity, we therefore have to see whether the constraints postulated in the present version of the D\&E framework do or do not have a counterpart in MP.

As in most work in OT-syntax, the constraint STAY in (14) plays an important role in D\&E. This constraint has its counterpart in MP in economy principles like Procrastinate, Fewest Steps, and the like. Other economy constraints may be *Merge, mentioned in fn. 2, and Grimshaw's (1997) NoLexM.

$$
\text { STAY: *t }
$$

As the discussion of (9) above has shown, the economy constraint STAY interacts with the set of constraints that constitute the constraint family EPP (F) repeated below as (15). The constraint family EPP (F) is concerned with $\mathrm{C}_{\mathrm{HL}}$, and can be 
compared to the EPP-features (or feature strength), which drive movement in MP. Constraints that are part of this family are CASE and AGREEMENT, and possibly also TENSE, WH, TOPIC, FOCUS, NEG, etc. ${ }^{5}$

(15) EPP (F): probe F attracts its goal.

(i) CASE: a case-feature attracts its goal.

(ii) AGREEMENT: $\Phi$-features attract their goal.

(iii) etc.

Another $\mathrm{C}_{\mathrm{HL}}$ constraint proposed in Broekhuis (2000) is EPP, which requires the subject position of the clause to be filled and which is of course borrowed from the P\&P framework. Sect. 3.2 will show, however, that EPP can be reduced to one of the EPP (F) constraints and hence need not be stipulated separately. If so, constraints of the EPP (F) family in (15) exhaust the set of $\mathrm{C}_{\mathrm{HL}}$ constraints, which entails that the number of $\mathrm{C}_{\mathrm{HL}}$ constraints equals the number of the postulated uninterpretable features.

The Interface constraints bear on the semantic component SEM or the phonological component PHON. The SEM constraints adopted in Broekhuis $(1999,2000)$ are related to the information structure of the clause: ALIGNFOCUS in (16a), which was adapted from Costa (1998), and D-PRONOUN in (16b), which is based on Diesing (1997). ${ }^{6}$ These SEM constraints find their parallel in the interpretive complex Int postulated in Chomsky's (2001, p. 31), which includes at least information about the dichotomy between new and old information. One of the aims of this article is to find out a little more about the set of constraints that make up this interpretive complex. In Sect. 3.1, for example, I will argue that this set includes the constraint SCOPE in (16c), adapted from Diesing (1997).

(16) a. ALIGNFOcus: The prosodically unmarked focus is the rightmost constituent in its clause.

b. D-PRONOUN: A (d-linked) definite pronoun must be $v$ P-external: $*\left[{ }_{v \mathrm{P}} \ldots \operatorname{pron}_{[+\operatorname{def}]} \ldots\right]$.

c. SCOPE: relative scope corresponds to hierarchical order.

\footnotetext{
${ }^{5}$ Generalizing Chomsky's (1995b, ch.3) suggestion that $w h$-features are universally strong to all [ + affect] features, Broekhuis and Dekkers (2000) argued that constraints like wH, TOPIC, FOCUS, NEG are not needed, since movement of the goals of the [+ affect] features is forced by semantic considerations. It is not entirely clear to me whether this conclusion can still be maintained under the present Agree-based approach; it probably can if we assume that movement of operators is needed for scope assignment. Since this question does not play a role in the present discussion, I will leave it to future research.

${ }^{6}$ Alignfocus is a gradient constraint. This means that it is interpreted such that each constituent following the focus of the clause results in a violation of this constraint; if the focus is followed by two constituents this gives rise to two violations. D-PRONOUN, as formulated in (16b), looks like some sort of filter; Vogel (2004) has shown that this constraint can probably be reduced to more primitive PHON constraints.
} 
The PHON constraints are of the type proposed by Pesetsky (1998), such as LE(CP) and TEL in (17), which were also adopted in Broekhuis and Dekkers (2000). These PHON constraints do not have a counterpart in MP, which is due to the fact that, to my knowledge, MP has had nothing to say so far about, e.g., the doubly filled complementizer phenomena discussed in these papers. Another PHON-constraint is AFFIX, which requires that an affix be phonologically supported. This is of course a reformulation of the Stray Affix Filter, which is also adopted in MP.

(17) a. LE (CP): The first pronounced word in CP is a function word related to the main verb of that $\mathrm{CP}$ (in effect the complementizer that or the inflectional element to).

b. TEL: do not pronounce function words.

The brief overview above suggests that MP and D\&E (insofar as they can be compared) have a descriptive apparatus of more or less the same size. Furthermore it has been shown that D\&E and OT differ in that the former assumes that the universal set of constraints $\mathrm{CON}$ is much more restricted than is normally assumed (cf. (12) and (13)).

\subsection{Conclusion}

This section has provided an updated version of the D\&E framework originally proposed in Broekhuis and Dekkers (2000) and Broekhuis (2000), and has compared it to MP. It turns out that MP and D\&E have a descriptive apparatus of more or less the same size. Further, MP and D\&E are facing a similar task in that they both have to identify the features that may trigger movement. The frameworks differ in that they provide different answers to the question of what determines whether the movement does actually take place. Recent versions of the MP assume that movement is forced by the presence of an EPP-feature, and in Chomsky (2001) it is assumed that the question whether this EPP-feature is present or not depends on properties of the interpretative complex Int. In D\&E the answer takes the form of an optimality-theoretic evaluation, as indicated in (9) and (10), repeated here as (18).

(18) a. weak ranking: STAY $\gg \operatorname{EPP}(\mathrm{F})$

b. strong ranking: $\operatorname{EPP}(\mathrm{F}) \gg$ STAY

c. A $\gg \operatorname{STAY} \gg \operatorname{EPP}(\mathrm{F})$ (if A favors movement, 'Procrastinate' is overruled)

d. в $\gg \operatorname{EPP}(\mathrm{F}) \gg \operatorname{STAY}$ (if B disfavors movement, 'Strength' is overruled) 
The constraint rankings in (18a) and (18b) determine whether a certain uninterpretable feature $F$ 'normally' does or does not trigger movement of its goal, or, in MP terms, has or does not have an EPP-feature. The constraints A and в in (18c) and (18d) determine whether the "normal' case can be overridden, and thus correspond to Chomsky's interpretative complex Int.

Given that the descriptive apparatuses of MP and D\&E are comparable in size, we have to take recourse to other criteria in making a choice between the two approaches. And the proof of the pudding is, of course, in the eating: which proposal provides the most elegant solutions for the problems under consideration and the best description of the facts? I hope to have already shown in Broekhuis (2000) that the D\&E framework has certain advantages over MP in its account of Scandinavian object shift and Dutch/German scrambling. This article will show that this account also makes certain predictions with respect to movement of the subject, which do not follow from, e.g., Chomsky's (2001, ex. (61)) account of object shift. Insofar as these predictions are correct, this also favors the D\&E approach over MP.

\section{A comparison of object shift and subject shift}

The introduction to this article has already discussed that the constraint ranking in (4), repeated here as (19a), expresses that the object is attracted by $\mathrm{V}$ and obligatorily moves into position $\mathrm{OBJ}_{2}$, thus giving rise to the $\mathrm{OV}$ order. Subsequently it is attracted by $v$ into position $\mathrm{OBJ}_{3}$ provided that it is not part of the focus of the clause. The latter movement is what is referred to as scrambling or object shift; see Broekhuis $(1999,2000)$ for detailed analysis.

$$
\begin{aligned}
& \text { a. Dutch: AGREEMENT } \gg \text { ALIGNFOCUS } \gg \text { CASE } \gg \text { STAY } \\
& \text { b. }\left[\mathrm{OBJ}_{3} \ldots v\left[\mathrm{OBJ}_{2} \ldots \mathrm{VOBJ}_{1}\right]\right]
\end{aligned}
$$

Since the constraints AGREEMENT and CASE simply require that $\Phi$ - and case features attract their goals, they do not distinguish between subjects and objects. Consequently, the prediction is that subjects and objects behave alike. This means that the case features on I should only trigger subject shift when the subject is part of the presupposition of the clause. Section 3.1 will show on the basis of well-known facts that this prediction is indeed borne out, thus providing evidence in favor of the assumption that subject shift and object shift are essentially the same operation. An obvious problem is, however, that the ranking in (19) also wrongly predicts that the $\Phi$-features on I should obligatorily trigger subject shift irrespective of whether the subject is part of the focus or of the presupposition of the clause. Section 3.2 will provide a solution for this problem. In what follows I will adopt the following two standard assumptions from the literature on object shift: (i) the object and the subject are both base-generated to the right of sentence adverbs like waarschijnlijk 'probably', which I provisionally assume to be adjoined to $v \mathrm{P}$; (ii) the landing 
site of object/subject shift is to the left of these sentential adverbs. For a more detailed discussion of the derivations involved, I refer to Sect. 5.

\subsection{Object shift, NP-movement, and case}

The examples in (20) show that object shift of a definite (in this case, possessed) noun phrase is apparently optional. Object shift must apply, however, when the noun phrase is part of the presupposition of the clause, whereas it cannot apply when the noun phrase is part of the focus of the clause. In the former case sentence accent is normally assigned to the verb (cf. (20b)), and in the latter to the object (cf. (20a)); sentence stress is indicated by means of underlining.
a. dat Jan waarschijnlijk mijn huis koopt. that Jan probably my house buys 'that Jan will probably buy my house.'
b. dat Jan mijn huis waarschijnlijk koopt.

The examples in (21) show that non-specific, indefinite noun phrases never shift, which is due to the fact that they are necessarily part of the focus of the clause.
a. dat Jan waarschijnlijk een huis zal kopen. that Jan probably a house will buy 'that Jan probably will buy a house.'
b. *dat Jan een huis waarschijnlijk zal kopen.

The claim that non-specific indefinite objects do not shift does not entail that specific indefinite objects must shift. Just like definite objects, specific indefinite objects only shift when they are part of the presupposition of the clause. Consequently, non-shifted indefinite objects like twee artikelen in (22a) can have either a specific or a non-specific reading; the shifted object in (22b), on the other hand, has only a specific reading. ${ }^{7}$
a. dat Jan waarschijnlijk twee artikelen zal lezen. that Jan probably two articles will read 'that Jan will probably read two (of the) articles.'
b. dat Jan twee artikelen waarschijnlijk zal lezen. that Jan two articles probably will read 'that Jan will probably read two of the articles.'

Finally, the examples in (23) show that normally definite pronouns obligatorily shift, which is due to the fact that they are never part of the focus of the clause.

\footnotetext{
7 The notions of non-specific and specific indefinite noun phrase are normally described as 'unknown to speaker and hearer' and 'unknown to hearer only', respectively. Specific indefinite NPs can often be paraphrased by means of a partitive phrase: under its specific reading twee artikelen in (22) is construed as 'two of the articles'.
} 
Under the assumption that the case-position precedes the sentence adverb, this is precisely what the ranking ALIGNFOCUS $\gg$ CASE $\gg$ STAY predicts.
a. *dat Jan waarschijnlijk het koopt. that Jan probably it buys 'that Jan probably will buy it.'
b. dat Jan het waarschijnlijk koopt.

For completeness' sake, note that the obligatoriness of pronoun shift holds only when the sentence has a more or less 'neutral' intonation pattern, that is, with main stress on the verb. Giving emphatic accent to the pronoun (which is only possible when the pronoun refers to a [+animate] entity) voids the need for pronoun shift.

(24) Je hebt waarschijnlijk HEM gezien.
you have probably
You probably saw HIM.'

Now, consider the corresponding examples involving a subject. The examples in (25) show that a definite noun phrase acting as the subject need not be moved into the 'regular' subject position adjacent to the complementizer, but may remain in a lower position (probably SpecvP). As in the case of object shift, the application of subject shift depends on the information structure of the clause. The subject can only remain in situ when it is part of the focus of the clause, which also in this case is normally marked by assigning main accent to the subject; see (25a). When the subject is part of the presupposition, sentence stress is assigned to some other element, e.g., the head of the direct object; see (25b).
a. dat waarschijnlijk that probably
de buurman
Jans huis koopt.
'that the neighbor is probably buying Jan's house.'
b. dat de buurman waarschijnlijk Jans huis koopt.

The examples in (26) show that non-specific, indefinite noun phrases do not shift into the regular subject position. The shift is possible, but then the noun phrase receives a specific interpretation (cf., e.g., De Hoop and Swart 1990).
a. dat waarschijnlijk twee studenten Jans huis zullen kopen. two students that probably Jan's house will 'that two (of the) students will probably buy Jan's house.'
b. dat twee studenten waarschijnlijk Jans huis zullen kopen. that two students probably Jan's house will buy 'that two of the students will probably buy Jan's house.' 
The claim that non-specific indefinite subjects do not shift does not imply that specific indefinite subjects must shift. Just like definite subjects, specific indefinite subjects only shift when they are part of the presupposition of the clause. Consequently, non-shifted indefinite subjects like twee studenten in (26a) can have either a specific or a non-specific reading. ${ }^{8}$

The examples in (27), finally, show that definite pronouns must shift to the regular subject position (provided that it is not assigned emphatic accent; cf. the discussion of (24)).
a. *dat waarschijnlijk ik zijn huis koop. that probably I his house buy
b. dat ik waarschijnlijk zijn huis koop. that I probably his house buy
'that I probably buy his house.'

The unacceptability of (27a) also shows that we cannot account for (25) and (26) by assuming that the sentential adverb can optionally be adjoined to TP, as was suggested by one of the reviewers, since this would wrongly predict (27a) to be acceptable (unless it could be shown that pronouns move into a position higher than TP, for which Dutch provides no evidence; object pronouns normally do not precede the subject).

The discussion above shows that, as predicted by the subranking ALIGNFOCus > CASE $\gg$ STAY, the movement behavior of objects and subject is similar when they have the form of a definite, an indefinite, or a pronominal NP. This is also the case when they are of some other noun phrase type. I will give two more examples here (see. Broekhuis et al. 2003 for a more complete overview). First consider the examples in (28). The object in (28a) has an existential interpretation: Jan is reading something that is probably a bestseller (or, alternatively, Jan is doing something, which is probably reading a bestseller). The object in $\left(28 \mathrm{a}^{\prime}\right)$, on the other hand, has a generic reading: it expresses that bestsellers are likely to be read by Jan. The same is even clearer in (28b-b'): (28b) expresses that Jan generally reads bestsellers, whereas (28b') expresses that most bestsellers are read by Jan. The examples in (28) therefore show that generic NPs must undergo object shift.
a. dat Jan waarschijnlijk een bestseller leest. that Jan probably a bestseller reads
$a^{\prime}$. dat Jan een bestseller waarschijnlijk leest.
b. dat Jan meestal een bestseller leest.
that Jan generally a bestseller reads
$b^{\prime}$. dat Jan een bestseller meestal leest.

\footnotetext{
${ }^{8}$ Placing expletive $e r$ in front of the adverbial phrase disambiguates example (26a): in that case, only the non-specific reading survives. I have little to say about the expletive, although I want to note that its distribution is not restricted by properties of the subject only (see, e.g., Bennis 1986 for extensive discussion). Further it must be noted that insertion of er is not motivated by the EPP (after all, then we would also predict an expletive to appear in examples like (25a)) but rather signals that the clause does not contain any presupposed material.
} 
Let us provisionally assume a constraint GENERIC in (29a), which prohibits generic NPs in $v$ P-internal positions (cf. Diesing's 1992, Mapping Hypothesis). When the ranking is given as in (29), we correctly account for the fact that generic noun phrases obligatorily undergo object shift.
a. GENERIC: $*\left[{ }_{\nu} \mathrm{P} \ldots \mathrm{DP}_{\mathrm{GEN}} ..\right]$
b. GENERIC $\gg$ ALIGNFOCUS $\gg$ CASE $\gg$ STAY

Since the constraints do not explicitly refer to objects, we predict that generic subjects must also evacuate the $v \mathrm{P}$, that is, they must be moved into SpecIP. The examples in (30) show that this prediction is borne out for both singular and plural indefinite NPs. In the prime-less examples the subject is presumably in SpecvP and receives an existential interpretation, whereas in the primed examples the subject is construed generically.
a. dat er meestal een nijlpaard in het water ligt. that there generally a hippopotamus in the water lies 'that there is generally a hippopotamus lying in the water.'
$a^{\prime}$. dat een nijlpaard meestal in het water ligt. that a hippopotamus generally in the water lies 'that a hippopotamus generally lies in the water.'
b. dat er meestal nijlpaarden in het water liggen. that there generally hippopotami in the water lie 'that there are generally hippopotami lying in the water.'
$\mathrm{b}^{\prime}$. dat nijlpaarden meestal in het water liggen. that hippopotami generally in the water lie 'that hippopotami generally lie in the water.'

Secondly, consider the examples in (31). The difference between (31a) and (31b) concerns the relative scope of the adverb vaak 'often' and the universally quantified noun phrase alle boeken 'all books'. Example (31a) expresses that it holds for each of the books individually that they are often taken along by Jan: the contention can be true if the number of books is ten and Jan never takes more than three books with him. Example (31b), on the other hand, expresses that John often takes along the full set of books: the contention is false if the number of all books is ten and Jan never takes more than three books with him.
a. dat Jan alle boeken vaak meeneemt. $(\forall>$ vaak $)$ that Jan all books often takes.along
b. dat Jan vaak alle boeken meeneemt. (vaak $>\forall$ )

To a large extent, scope relations between XPs in the middle field can be read off of the linear order of the clause in Dutch. This could be accounted for by 
assuming the constraint SCOPE in (16c) above, which requires that scope relations correspond to hierarchical (thus linear) order. ${ }^{9}$ When we assume the partial ranking in (32), object shift is blocked in (31b). What is crucial here is that this ranking does not only block object shift in (31b), but also subject shift in $(33 b)$, as expected. ${ }^{10}$

Dutch: SCOPE $\gg$ CASE $\gg$ STAY
a. dat alle studenten vaak hier zijn. $(\forall>$ vaak) that all students often here are
b. dat vaak alle studenten hier zijn. (vaak $>\forall$ )

Of course, the present formulation of the constraints GENERIC and SCOPE is pretty coarse, and it might well be the case that their final formulation might be more abstract with wider empirical ramifications. At this point, however, I am focusing on finding the set of conditions that determine whether object/subject shift must or cannot apply, that is, I am trying to determine what Chomsky's (2001) interpretative complex Int consists of. In order to gain more insight in the constraints that make up Int, further comparison of object shift and subject shift with other noun phrase types is important. I will not explore the issue any further here, but instead turn to a more problematic aspect of the

\footnotetext{
${ }^{9}$ The interpretations given here are at least the highly preferred ones; one of the reviewers apparently also allows an inverted scope reading for example (31a), which suggests that (s)he is able to reconstruct the shifted object - for the speakers I consulted (including myself) this is marginally possible at best and requires that the DP be contrastively focused, in which case the word order probably results from $\mathrm{A}^{\prime}$-movement into SpecFocusP. Of course, postulating SCOPE does not imply that relative scope can always be read off from linear order. For example, in languages where STAY outranks SCOPE (English might be such a language), the optimal candidate may violate SCOPE. This would allow us to handle scope ambiguities without having to resort to Quantifier Raising. Further, the movement which gives rise to the desired order must satisfy LAST RESORT. This accounts for the fact that when the universally quantified DP is the complement of a PP, scope ambiguities do arise in Dutch. Example (i), adapted from Den Besten and Broekhuis (1992), is ambiguous between the $\exists \forall$ reading and the $\forall \exists$ reading. Actually, the latter is the preferred one for extra-linguistic reasons. In passing, note that it is also possible to say dat Peter in elke vaas een bloem zet but this requires a special intonation pattern, which might indicate that the PP then has been moved into, e.g., SpecFocusP.
}

(i) dat Peter een bloem in elke vaas zet.

that Peter a flower in every vase put

'that Peter puts a flower in every vase.'

\footnotetext{
${ }^{10}$ In passing, note that the examples in (31) and (33) show again that it is not the numeration that determines the candidate set (cf. fn. 3). The a- and b-examples are based on the same numeration, so that MP predicts that the a-examples should be blocked by the b-examples as the less economical derivations - in OT terminology: it involves one additional violation of STAY. By assuming that the candidates in the candidate set must have the same meaning, however, the a- and b-examples are not part of the same candidate set, so that they cannot be compared, which correctly predicts that they all are possible word orders.
} 
analysis: the fact that AGREEMENT does not seem to force the application of subject shift.

\subsection{Object shift, NP-movement, and agreement}

The introduction to this article has shown that the partial ranking AGREEMENT $>>$ ALIGNFOCUS $\gg$ STAY accounts for the OV nature of Dutch. Since considerations of information structure cannot block agreement-driven object shift, the direct object obligatorily moves from its postverbal base position into the specifier of $\mathrm{V}$, which is assumed to have uninterpretable $\Phi$-features. When the evaluator compares the two substructures in (34), (34b) will be selected as the optimal candidate. ${ }^{11}$

$$
\begin{aligned}
& \text { a. } \ldots\left[\ldots \mathrm{V}_{[+\Phi]} \mathrm{OBJ}_{[+\Phi]}\right] \\
& \text { b. } \ldots\left[\mathrm{OBJ}_{[+\Phi]} \mathrm{V}\left[\ldots t_{\mathrm{V}} t_{\mathrm{OBJ}}\right]\right]
\end{aligned}
$$

Now assume that finite I also has uninterpretable $\Phi$-features, so that we have the structures in (35). Also in this case the evaluator will select the b-candidate as the optimal one. This means that the subject obligatorily moves into SpecIP, that is, into the 'regular' subject position.

$$
\begin{aligned}
& \text { a. }\left[\mathrm{I}_{[+\Phi]} \ldots\left[{ }_{v \mathrm{P}} \operatorname{Subj}_{[+\Phi]} v[\mathrm{vP} \ldots . .]\right]\right] \\
& \text { b. }\left[\operatorname{Subj}_{[+\Phi]} \mathrm{I} \ldots\left[{ }_{v \mathrm{P}} t_{\mathrm{Subj}} v[\mathrm{vP} \ldots . .]\right]\right]
\end{aligned}
$$

As we have seen in Sect. 3.1, this prediction is wrong. So, we have to ask ourselves whether this refutes the general framework we are pursuing or whether something special is going on in the case of the subject. If the latter, there are two possibilities: the subject differs in some way from the object, as a result of which the subject need not be attracted by I, or I differs in some way from $\mathrm{V}$, as a result of which it need not attract the subject.

It is easy to show that the absence of subject shift is not due to some difference between the subject and the object, but to some difference between I and V. First, consider the examples in (36), which contain the dyadic unaccusative verb overkomen 'to happen', and in which the definite subject

\footnotetext{
11 The movement of $\mathrm{V}$ in (34b) follows from the assumption that heads do not have multiple specifiers but may create an additional phrase structure layer when attracting some XP (cf. Nash and Rouveret 1997; Grimshaw 1997). I assume that moving the object into the empty specifier position of (34a) is blocked by Chomsky's (2000) version of $\theta$-theory according to which "pure merge in theta position is required of (and restricted to) arguments". The combination of these assumptions has the effect that movement is allowed only when we create an extended projection. These assumptions are, of course, not essential ingredients in the D\&E framework or in the present analysis, but I maintain them for the reasons indicated in Broekhuis (2000).
} 
de ergste rampen 'the most terrible disasters' can either follow the indirect object or be placed into the 'regular' subject position (cf. Den Besten 1985 and many others).
a. dat het meisje $e_{\text {dat }}$ waarschijnlijk that the girl probably
de ergste
the most. terrible disasters overkwamen. happened 'that the most terrible disasters probably happened to the girl.'
b. dat de ergste rampen $_{\text {nom }}$ het meisje dat $_{\text {overkwamen. }}$

That the case features on I do not force movement of the subject into SpecIP follows from the discussion in Sect 3.1: when the definite subject belongs to the focus of the clause, as in (36a), movement is blocked by ALIGNFOCUs; when it is part of the presupposition of the clause, as in (36b), movement must apply. The examples in (37) and (38) show that indefinite and pronominal subjects also behave as expected.
a. dat het meisje dat $_{\text {waarschijnlijk erge rampen }}$ nom overkwamen. that the girl probably terrible disasters happened
'that terrible disasters probably happened to the girl.'
b. ${ }^{\#}$ dat erge rampen nom het meisje $_{\text {dat }}$ overkwamen.
a. *dat het meisje zij overkwamen. that the girl they happened 'that they happened to the girl.'
b. dat zij het meisje overkwamen.

The important thing to note at this point is that the subject must precede the verb in clause-final position in all cases. Since the subject is an internal argument of the verb, it can only end up in this position if it has moved from its postverbal base position into the preverbal position. Since $v$ associated with unaccusative verbs does not have accusative case features, this movement must have been triggered by the uninterpretable $\Phi$-features on $\mathrm{V}$, that is, agreement. This implies that the subject occupies a $v$ P-internal position in (36a) and (37a). That this is indeed the case is also suggested by the fact that the subject must follow the sentential adverb waarschijnlijk; placing the subject in between the dative object and the adverbial phrase would give rise to a highly marked result in (36a) and be straightforwardly excluded in (37a). Note that the indirect object may precede or follow the sentential adverb, which is of course expected given that dyadic unaccusative verbs are able to assign (structural) dative case. The fact that the subject is attracted by the $\Phi$-features on V but not by those of I suggests that the 
problem under discussion is not caused by some difference between subjects and objects, but by some difference between I and V. ${ }^{12}$

So the next question is: In what respect are $\mathrm{V}$ and I different? I will argue that the difference lies in the fact that they do not contain the same set of uninterpretable $\Phi$-features. In other words, the problem is due to the fact that the proposal in Broekhuis $(1999,2000)$ is based on too simple a view on $\Phi$-features. Once we have a better understanding of these features, everything will fall in place.

There is a general tendency to look upon $\Phi$-features as a semantic unit: $\Phi$-features are the gender, number, and person features of noun phrases. Also in syntax the $\Phi$-features are normally treated as a complex object, a feature bundle. There are, however, good reasons to not adopt such a view on the $\Phi$-features. Note that $\Phi$-features of nouns fall into two categories: the features [number] and [person] are features with clear semantic import, whereas [gender] is rather a formal class marker, which may but need not have semantic import. I will assume that this distinction is reflected in the way these features are introduced into the computation: [gender] is clearly a lexical property of the noun, so that it must be introduced into the derivation by the noun itself; the features [number] and (as I will claim) [person], on the other hand, are not inherent features of the noun but semantically relevant features that are introduced by the functional heads NUM and D, respectively. This distinction is, of course, reminiscent of Chomsky's (1995b, p. 231) distinction between intrinsic and optional features.

In short, the fact that we think of $\Phi$-features as a feature bundle is not because they constitute a unit of some sort, but because they are normally combined within a single DP. It is, therefore, not a logical necessity that the three always co-occur. They may, as in (39a), where we are dealing with a definite noun phrase headed by a count noun. But it may also be the case that one of the functional heads (hence $\Phi$-features) is missing: in (39b) this is

\footnotetext{
${ }^{12}$ Susi Wurmbrand (p.c.) has suggested that we might also tackle this problem by making Inflection and the verb more parallel. This can be done by assuming that, just like the verb $(\mathrm{V}+v)$ defines two potential landing sites for the object, inflection defines two potential landing sites for the subject (cf. Bobaljik and Jonas 1996; Bobaljik and Thráinsson 1998). We might then assume that, in accordance with the Dutch constraint ranking, subject shift into the lower landing site is obligatorily triggered by the agreement features, whereas subject shift into the higher landing site is triggered by the case features and depends on the information structure of the clause. Given that the object precedes the subject in (36a) and (37a), a solution of this kind would imply that the lower landing site of the subject is dominated by a (higher) landing site of the object(s). This cannot be maintained, however, because this would wrongly predict that in regular (di)transitive examples it would also be possible for the (in)direct object to precede the subject when the latter is part of the focus of the clause; cf. (i). I therefore reject this assumption and stick to the standard assumption that the subject remains $v \mathrm{P}$ internally in examples like (36a) and (37a).
}

\begin{tabular}{|c|c|c|c|c|}
\hline $\mathrm{a}$ & $\begin{array}{l}\text { dat } \\
\text { that }\end{array}$ & $\begin{array}{l}\text { Marie }_{\mathrm{S}} \\
\text { Marie }\end{array}$ & $\begin{array}{l}\text { Jan/hem } \\
\text { Jan/him }\end{array}$ & $\begin{array}{l}\text { het boek } \\
\text { the book }\end{array}$ \\
\hline & $*$ dat & $\mathrm{Jan} /$ hem $_{\mathrm{IO}}$ & Marie $_{S}$ & het boek ${ }_{\mathrm{DO}}$ \\
\hline & $*$ dat & het boek ${ }_{\mathrm{DO}}$ & Marie $_{S}$ & $\mathrm{Jan} /$ hem $_{\mathrm{IO}}$ \\
\hline & *dat & $\mathrm{Jan} /$ hem $_{\mathrm{IO}}$ & het boek ${ }_{\mathrm{DO}}$ & Marie $_{\mathrm{S}}$ \\
\hline
\end{tabular}


illustrated by a definite noun phrase headed by a non-count noun and in (39c) by an indefinite noun phrase headed by a count noun. In (39d) we are dealing with an indefinite noun phrase headed by a non-count noun with no functional head at all (hence only a gender feature). Assuming something like this would be entirely in line with the Bare Phrase Structure approach developed in Chomsky 1995a). ${ }^{13}$

\section{- Structure}

a. $\left[\mathrm{D}_{\text {[person] }}\left[\mathrm{NUM}_{[\text {number }]}\left[\mathrm{N}_{\text {[gender }]}\right]\right]\right.$

b. $\left[\mathrm{D}_{\text {[person] }}\left[\mathrm{N}_{\text {[gender }]}\right]\right]$

c. $\left[\mathrm{NUM}_{[\text {number] }}\left[\mathrm{N}_{\text {[gender }]}\right]\right]$

d. $\left[\mathrm{N}_{\text {[gender }]}\right]$
- Example

de vier $/ \varnothing$ mannen

the four $\varnothing$ men

de wijn

the wine

vier $/ \varnothing$ mannen

four $/ \varnothing$ men

wijn

wine

If it is true that the $\Phi$-features on noun phrases are introduced into the derivation by separate heads, there is no reason to assume that the uninterpretable $\Phi$-features that trigger movement of the noun phrase always make up a complete $\Phi$-feature bundle: V may contain a different subset of the $\Phi$-features than I. That something like this is indeed the case is suggested by the overt morphology that is used to express object and subject agreement. In the Romance languages, for instance, object agreement typically involves gender (and number), whereas subject agreement involves person (and number). This is illustrated in (40), taken from Burzio (1986): the object clitic la agrees in gender and number with the participle, whereas the subject Giovanni agrees with the finite verb in person and number.
Giovanni la ha accusata.
Giovanni her has $_{3 s g}$ accused $_{\text {fem }, s g}$
'Giovanni has accused her.'

Let us by way of hypothesis assume that the following holds, putting aside the question why the distribution of the uninterpretable $\Phi$-features is as it apparently is; cf. Chomsky (2001) for a discussion of case assignment that exploits the intuition in (41a).
a. V has the uninterpretable $\Phi$-features [gender] and [number]
b. I has the uninterpretable $\Phi$-features [person] and [number]

\footnotetext{
${ }^{13}$ This does not imply, of course, that the features must be phonologically supported. Features may also be inserted into the structure by abstract functional heads. The behavior of generic noun phrases (e.g., the fact that they may not occur in expletive constructions: *there is red wine healthy) suggests that they contain a [person] feature, that is, an empty D; cf. (44) below. See Longobardi (1994) and later work for further discussion.
} 
The solution to the problem posed by the subject-object asymmetry with respect to scrambling now suggests itself. Apparently, I was wrong in assuming a single constraint AGREEMENT for all cases of agreement: instead we must assume separate constraints, one for each $\Phi$-feature, as in (42).
a. AGR PERSON $_{\text {[ }}$ [person] attracts its goal.
b. AGR NUMBER $_{\text {[ }}$ [number] attracts its goal.
c. $\mathrm{AGR}_{\mathrm{GENDER}}$ : [gender] attracts its goal.

The desired distinction can now be made by assuming the ranking in (43). The partial ranking $A_{G R_{\text {GENDER }}} \gg$ ALIGNFOCUS $\gg$ STAY expresses that the gender feature on $\mathrm{V}$ is responsible for the $\mathrm{OV}$ nature of Dutch by triggering movement of the postverbal object into preverbal position. As before, the partial ranking ALIGNFOCUS $\gg$ CASE $\gg$ STAY expresses that the case feature on $v /$ I triggers movement of the object/subject provided that it is part of the presupposition of the clause. The constraints $\mathrm{AGR}_{\text {PERSON }}$ and $\mathrm{AGR}_{\mathrm{NUMBER}}$ allow but do not force movement of the subject, and are therefore outranked by ALIGNFOCUS. Since the precise position of these constraints in the ranking cannot be determined on the basis of the data under discussion, we leave the ranking between STAY and these agreement constraints undetermined; this is expressed by placing the constraints between curly brackets.

$$
\begin{gathered}
\text { Dutch: } \\
\text { AGR }_{\text {GENDER }} \gg \text { ALIGNFOCUS } \gg \text { CASE } \gg\left\{\text { STAY, AGR } \text { AGUMBER }_{\text {PERSN }}\right\}
\end{gathered}
$$

By way of exercise let us see what the constraint ranking of English is. When we assume that the object remains in its base position, we have to assume that STAY outranks CASE, $\mathrm{AGR}_{\mathrm{GENDER}}$, and $\mathrm{AGR}_{\mathrm{NUMBER}}$. Given this conclusion there is only one option left to force subject shift: $A_{\text {GRERSON }}$ outranks STAY. Since subject shift in English is not sensitive to the information structure of the clause, AGR $_{\text {PERSON }}$ also outranks ALIGNFOCUs. This would give the English ranking in (44); since the constraints STAY and ALIGNFOCUS both militate against movement their relative order cannot be determined. Note that, since $A_{G R}{ }_{\text {PERSON }}$ forces subject shift in English, there is no need to stipulate a separate constraint EPP, which would be needed if we assumed a simple constraint AGREEMENT outranked by CASE.

$$
\text { AGR } \left._{\text {PERSON }} \gg\{\text { ALIGNFOCUS, STAY }\} \gg \quad \text { CASE, AGR } \text { GENDER }, \mathrm{AGR}_{\text {NUMBER }}\right\}
$$

In fn. 1 we have seen, however, that there is compelling evidence for assuming that English has object movement triggered by the agreement features on $\mathrm{V}$, which is made invisible by subsequent V-to- $v$ movement. If so, we must conclude that $\mathrm{AGR}_{\mathrm{GENDER}}$ outranks STAY, so that the correct English ranking is not (44) but rather as given in (45):

(45) English: $\left\{\right.$ AGR $\left._{\text {PERSON }}, \mathrm{AGR}_{\text {GENDER }}\right\} \gg\{$ ALIGNFOCUS, STAY $\} \gg$ \{CASE, AGR NUMBER $\}$ 
Note that the proposal in (45) (as well as the one in (44)) is fully compatible with Chomsky's proposal that expletives are inserted in order to satisfy the EPP: the expletive there is a D-element, which is therefore adorned with a [person] feature and merging it into SpecIP would result in checking the person feature of $I^{14}$ At the same time, the Dutch ranking in (43) predicts that Dutch need not take recourse to an expletive. And this is true also, as is clear from the fact that SpecIP can remain empty in Dutch; see, for instance, the examples in (25a) and (33b). This leaves open the possibility that the Dutch element er, which is often considered the counterpart of English there, is not an expletive in Chomsky's sense (as was already suggested in fn. 8). And, actually, there is interesting evidence that Dutch er and English there are different. In Chomsky (2001, ex. (28-29)), it is shown that the expletive there blocks $w h$-movement of the subject, as in $\left(46 \mathrm{a}^{\prime}\right)$, whereas it does not block wh-movement of other phrases. In Dutch, on the other hand, the counterpart of (46a') is fully acceptable; see $\left(46 b^{\prime}\right)$. This can be understood better if er and there are different kinds of entities. ${ }^{15}$

(46) a. There were several packages placed on the table.

$a^{\prime}$. *How many packages were there placed on the table?

b. Er werden verscheidene pakjes op de tafel gezet. there were several packages on the table placed

$b^{\prime}$. Hoeveel pakjes werden er op de tafel gezet? how.many packages were there on the table placed

\section{A brief note on scrambling of PPs}

The discussion in Sect. 3 was confined to object (and subject) shift of DPs. The reason for this was that I claimed that this type of movement is triggered by the case features, and hence is an instance of A-movement. The claim that Scandinavian object shift is A-movement is supported by the fact that PPs cannot undergo this movement (Vikner 1994). The claim that Scandinavian object shift and

\footnotetext{
${ }^{14}$ For convenience, I adopt Chomsky's analysis of the expletive construction in the main text, despite the fact that I actually believe it to be incorrect for reasons that are not relevant now (cf. Broekhuis and Klooster 2001 for discussion). One of the reviewers correctly points out that, according to (44/45), the indefinite subjects in (ia) and (ib) should differ with respect to their feature constellation: in (ia), the NP a man should have a [person] feature, which is lacking in (ib). This conclusion also follows from the current analyses within MP: if the subject in (ia) does not have a person feature, the -Interpretable [person] feature on I cannot be checked and the derivation crashes. The conclusion that the subjects in (ia) and (ib) differ in their feature constellation is not surprising, since this might relate to several systematic (although sometimes subtle) meaning differences between the two constructions; cf. Milsark (1974, Sect. 6.2).
}

(i) a A man was shot in the bar

b There was a man shot in the bar.

${ }^{15}$ It does not explain it, of course. Note that the English data are not entirely undisputed; cf. Hoekstra and Mulder (1990, p. 45). 
Dutch/German scrambling are the same operation predicts that scrambling of PPs is excluded as well. At first sight, however, this prediction does not seem to be borne out: the PP complement op mijn opmerking in example (47), taken from Neeleman (1994b), can either follow or precede the adverbial phrase nauwelijks 'hardly'.
a. dat Jan nauwelijks
op mijn
opmerking
reageerde.
that Jan hardly
on my remarks
reacted
'that Jan hardly reacted to my remark.'
b. dat Jan op mijn opmerking nauwelijks reageerde.

Of course, the obvious way out would be to claim that we are dealing with $\mathrm{A}^{\prime}$-movement in (47b), e.g., movement into some FocusP. Neeleman notices, however, that the PP in (47b) does not require contrastive focus accent, and therefore dismisses this suggestion. If we want to conclude for this reason that the type of scrambling discussed in the previous section and the type of scrambling in (47b) are the same, there are two possibilities. Either we follow Neeleman (1994b) in assuming that scrambling is not movement, or we follow Haeberli (2002) in assuming that in (47b) we are dealing with A-movement of a more abstract type (according to his proposal: A-movement as the result of categorial feature checking). I will argue that both claims are wrong because the premise that (47b) involves a similar kind of movement as the cases of object shift in the previous sections is not empirically supported.

The first reason to assume that the movement in (47b) is different from object shift has to do with the distribution of PPs that contain a definite pronoun. The primed examples in (48) show that scrambling is only possible when the pronoun has its non-reduced form; use of a weak pronoun is impossible. This shows that the scrambled PP must be assigned stress, whereas object shift normally has the effect of destressing the moved element. This in turn suggests that Neeleman is actually wrong in assuming that the PP is not assigned focus accent in (47b).
a. dat Jan nauwelijks naar hem/'m luisterde. that Jan hardly to him listened
'that Jan hardly listened to him.'
$a^{\prime}$. dat Jan naar hem/*'m nauwelijks luisterde
b. dat Jan nauwelijks naar haar/'r keek. that Jan hardly at her looked
'that Jan hardly looked at her.'
$b^{\prime}$. dat Jan naar haar/*'r nauwelijks keek

A second reason to assume that the movement in (47b) is of a different type is that scrambling of the PP is only possible with a restricted set of adverbial phrases. ${ }^{16}$

\footnotetext{
${ }^{16}$ It is not entirely clear at this moment which types of adverbial phrases do or do not allow this movement: my impression is that scrambling of PPs is mainly possible with negative adverbs like nauwelijks 'hardly', quantified adverbs like vaak 'often', and modal adverbs like waarschijnlijk 'probably'. Since little is known about the conditions under which PP scrambling is (im)possible, it is clear that this issue requires more research in the future.
} 
When we replace the negative adverbial phrase nauwelijks in (47b) by the adverbial phrase gisteren 'yesterday', scrambling of the PP gives rise to a degraded result, as is illustrated in (49) with three different PP-complements. Object shift, on the other hand, can cross adverbs like gisteren: Ik heb dat boek gisteren gelezen 'I have read that book yesterday'. Recall that we only consider the cases with a more or less neutral intonation pattern; adding exhaustive focus accent to the PP complement or emphatic accent to the adverb may improve the unacceptable cases in the primed examples.

a. Jan heeft nauwelijks/gisteren op mijn opmerkingen gereageerd. Jan has hardly/yesterday on my remarks reacted

'Jan hardly reacted to my remarks.'/'Jan reacted to my remarks yesterday.'

$a^{\prime}$. Jan heeft op mijn opmerkingen nauwelijks/*gisteren gereageerd.

b. Jan heeft nauwelijks/gisteren naar Marie gekeken. Jan has hardly/yesterday at Marie looked 'Jan hardly looked at Marie.'/'Jan looked at Marie yesterday.'

$\mathrm{b}^{\prime}$. Jan heeft naar Marie nauwelijks/*gisteren gekeken.

c Jan heeft gisteren op vader gewacht. Jan has yesterday for father waited

'Jan was waiting for father yesterday.'

$\mathrm{c}^{\prime}$. *Jan heeft op vader gisteren gewacht.

Examples (50a\&a'), finally, show that scrambling of a PP-complement across an adverbially used PP is always blocked, whereas object shift across such adverbial PPs is always possible. Note further that the ungrammaticality of (50a) cannot be accounted for by some constraint that says that complements of a certain categorial type cannot be moved across an adverbial phrase of the same categorial type, since example (50b), in which a DP complement is moved across an adverbially used DP, is fully acceptable.

a. dat Jan <*op Marie $>$ na de vergadering <op Marie $>$ wachtte that Jan for Marie after the meeting waited 'that Jan waited for Marie after the meeting.'

$\mathrm{a}^{\prime}$. dat Jan $<$ het boek $>$ na de vergadering $<$ het boek $>$ wegbracht. that Jan the book after the meeting away.brought 'that Jan brought away the book after the meeting.'

b. dat Jan < dat boek $>$ deze middag < dat boek $>$ zal wegbrengen. that Jan that book this afternoon will away.bring

'that Jan will bring away that book this afternoon.'

The importance of this note on PP scrambling is that it shows that PP scrambling exhibits behavior that is untypical of object shift. I therefore conclude that it is movement of the $\mathrm{A}^{\prime}$-type, viz. Focus-movement. 
Consequently, examples like (47b) cannot be used to argue against the analysis defended in Sect. 3 that object shift is triggered by the case feature. $^{17}$

\section{Some speculations on 'short' object shift}

Although the discussion in Sect. 3 is encouraging, we are still far from arriving at a fully descriptively adequate theory on scrambling of the A-movement type. Given that we so far have only considered agreement and case driven movement, we have identified no more than two landing positions for object shift (see below). However, it is clear that the direct object may occupy more than two positions in the preverbal field. Example (51), for example, shows that there must be at least one additional landing site between the sentence adverb and the verb in clause-final position: this position is given in bold face.

(51) dat Jan < dat boek $>$ waarschijnlijk <dat boek $>$ snel/morgen $<$ dat boek $>$ that Jan that book probably quickly/tomorrow wegbrengt. away.brings

'that Jan will probably bring that book away quickly/tomorrow.'

The logic underlying the analyses in the previous sections therefore predicts there to be more landing sites available. Although it remains to be shown whether a movement approach like the one developed here can fully account for all the attested word order variations, this section will show that indeed more landing sites can be identified. I will focus on what I will call 'short' object shift, which moves the direct object into a position following sentence adverbs like waarschijnlijk and preceding VP-adverbs like snel/ morgen in (51)), and speculate a bit on the type of landing positions and triggers these movement involve.

\footnotetext{
${ }^{17}$ An important question raised by one of the reviewers is the following: If PP Scrambling is not A-movement, how does the preverbal placement of complement PPs arise? Here, I assume that the preverbal placement of the PP is not the result of leftward movement of the PP, due to the fact that the PP is actually not generated as the complement of V. Instead, P is generated VP-externally and attracts the DP-complement of the verb (cf. Kayne 2000). Evidence in favor of the assumption that $\mathrm{P}$ is generated VP-externally is provided by the constructions in (ia\&b): when the preposition is stranded, it cannot be pied piped by VP-topicalization, as would be predicted if the PP were basegenerated VP-internally (cf. Den Besten and Webelhuth 1990). The above implies that the preverbal placement of the PP is more basic than the postverbal placement; the latter can be derived along the lines of Barbiers (1995) by moving VP into the specifier of P.
}

(i) a [VP Gewacht] heeft hij er niet op. waited has he there not for

'He didn't wait for it.'

b *[VP Op gewacht] heeft hij er niet. 
Let us first consider in more detail the derivation of a transitive construction in Dutch and review the predictions made by the Dutch constraint ranking (43), repeated here as (52).

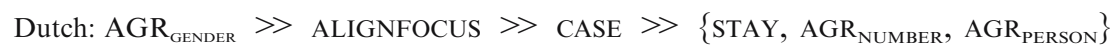

The first step in the derivation is merging $\mathrm{V}$ and the internal argument $\mathrm{OBJ}$, as in (53a): for concreteness' sake, assume that the direct object has a complete set of $\Phi$-features. According to (41a), V only has the uninterpretable features [gender] and [number]. The partial ranking $\mathrm{AGR}_{\text {GENDER }} \gg$ ALIGNFOCUS $\gg$ STAY predicts that the [gender] feature triggers movement of the object irrespective of whether the object is part of the focus or the presupposition of the clause, as in (53b). ${ }^{18}$ After the agreement-driven movement in (53b), the derivation continues with merger of the light verb $v$ and the external argument SUBJ, as in (53c). The question whether object shift applies or not, as in, respectively, (53d') and (53d), depends on the information structure of the clause: the partial ranking ALIGNFOCUS $\gg$ CASE $\gg$ STAY expresses that the case feature on $v$ trigger object shift only when the object is part of the presupposition of the clause.
a. $\left[\ldots \mathrm{V}_{\text {[gender,number }]} \mathrm{OBJ}_{[\Phi / \text { case }]}\right]$
b. $\left[\mathrm{OBJ}_{[\Phi / \text { case }} \mathrm{V}\left[\ldots t_{\mathrm{V}} t_{\mathrm{OBJ}}\right]\right]$
c. $\left[\mathrm{SUBJ}_{[\Phi / \text { case }]} v_{[\text {case }}\left[\mathrm{OBJ}_{[\Phi / \text { case }]} \mathrm{V}\left[\ldots t_{\mathrm{V}} t_{\mathrm{OBJ}}\right]\right]\right]$
d. $\left[\mathrm{SUBJ}_{[\Phi / \text { case }]} v\left[\mathrm{OBJ}_{[\Phi]} \mathrm{V}\left[\ldots t_{\mathrm{V}} t_{\mathrm{OBJ}}\right]\right]\right]$
$\left.\mathrm{d}^{\prime} . \mathrm{OBBJ}_{[\Phi]} v\left[\mathrm{SUBJ}_{[\Phi / \text { case }} t_{v}\left[\mathrm{OBJ}_{[\Phi / \text { case }} \mathrm{V}\left[\ldots t_{\mathrm{V}} t_{\mathrm{OBJ}}\right]\right]\right]\right]$

The next step in the derivation is the addition of I. Since I's two $\Phi$-features [person/ number] do not force movement of SUBJ in Dutch, whether the subject moves or not depends on whether it is part of the presupposition or of the focus of the clause: if the former, CASE forces subject shift; if the latter, ALIGNFOCus prohibits it. ${ }^{19}$ Note that $v$ is assumed to move into I for reasons given in Broekhuis (2000), as

\footnotetext{
${ }^{18}$ As was already mentioned in $\mathrm{fn} .11$ the movement of $\mathrm{V}$ in (53b) is forced by the assumption that heads do not have multiple specifiers but may create an additional phrase structure layer in order to facilitate checking. Also the movement of $v$ in $\left(53 \mathrm{~d}^{\prime}\right)$ is due to this ban on multiple specifiers. The question of whether movement of $v$ pied pipes $\mathrm{V}$ depends on the question whether $\mathrm{V}$ has moved to $v$, which is the case in main clauses but not in embedded clauses; see Broekhuis $(1999,2000)$ for a discussion of this.

${ }^{19}$ A problem with this proposal is that it is predicted that, given the right informational structural conditions, Dutch freely allows object-subject orders. Although such orders do indeed occur, they are possible only under special conditions, for example, when the object is a definite and the subject is an indefinite pronoun, as in example (i).

(i) dat hem waarschijnlijk niemand/*Jan wil ontmoeten that him probably nobody/Jan wants meet

This suggests that something is still missing in the present analysis, and that we need to add something like Müller's (2001) constraint PARALLel MOVEMENT or Fox and Pesetsky's (2005) theory of Cyclic Linearization, which both essentially aim at forcing the preservation of the underlying order of arguments. Both proposals are in principle compatible with the present framework; since investigating which is to be preferred would lead me too far afield, I leave this question to future research.
} 
a result of which movement of SUBJ into SpecIP satisfies the Minimal Link Condition (MLC).

Now, following the earlier assumption that sentence adverbs like waarschijnlijk 'probably' intervene between the two derived positions of the object, we correctly predict that the object may either precede or follow the adverb in (54).

$$
\ldots \mathrm{OBJ}_{3} \text { waarschijnlijk } \ldots \quad \mathrm{OBJ}_{2} \mathrm{~V} \mathrm{OBJ}_{1}
$$

Further, we predict that there is only one position for the object in between the sentence adverb and $\mathrm{V}$ in clause-final position. This prediction is, however, not borne out: example (55) shows that we must assume at least two positions for the object in this domain. So besides 'long' object shift into a position preceding the sentence adverb, there is also 'short' object shift into a position following the sentence adverb, but preceding the VP-adverbs. ${ }^{20}$
a. dat Jan waarschijnlijk morgen/snel dat boek leest. that Jan probably tomorrow/quickly that book reads 'that Jan will probably read that book tomorrow/quickly.'
b. dat Jan waarschijnlijk dat boek morgen/snel leest.

One might speculate that this problem with short object shift is only apparent and simply results from the fact that I have abandoned the use of multiple specifiers (see fn. 11/18). Assume that we do have multiple specifiers and that adjuncts are placed in the specifier of some head, more specifically, that VPadverbs are placed in one of the specifier positions of $\mathrm{V}$ and sentence adverbs in one of the specifier positions of $v$. The two orders in (55) could then be the result of a difference in the application of Merge and Attract/Move: when the object precedes the adverb, the latter has been merged before the former has been moved; when the linear order is the reverse, the order of the operations is also reversed. Although this might be a solution to the problem, it does not take into account that the two orders in (55) correlate with a subtle difference in meaning. The best way to describe this difference is perhaps in terms of prominence in the focus field. In the examples in (55) both the VP-adverb morgen/ snel and the direct object dat boek are part of the focus of the clause, but the element that is closest to the verb seems to be the most prominent part of the focus. $^{21}$ So, let us assume an additional gradient constraint PROMINENCE, a

\footnotetext{
${ }^{20}$ Note that 'short' object shift can also be found in the Mainland Scandinavian languages (cf. Broekhuis 2000). This of course strengthens the thesis underlying this research that Scandinavian object shift and Dutch/German A-scrambling are instances of the same movement process.

${ }^{21}$ Example (55a) also allows a reading in which the adverb morgen/snel is part of the presupposition. That this reading is available is, of course, not surprising given the fact that adverbs have a fixed position in the middle field of the clause. This, in its turn, is due to the fact that there are no features that could trigger adverb displacement in the middle field of the clause, so that adverbs also stay put when they are part of the presupposition of the clause, due to Last Resort. In the main text, I only consider the reading in which both the adverb and the object are part of the focus of the clause.
} 
preliminary definition of which is given in (56); see fn. 6 for the notion of gradient constraint.

$$
\begin{aligned}
& \text { PROMINENCE: The prominent part of the focus of the clause is the } \\
& \text { rightmost constituent in its clause. }
\end{aligned}
$$

Assuming the constraint in (56) does by itself not solve the problem concerning the word order variation in (55), since we do not know what landing site is involved, that is, what triggers the movement of the object. Under the assumptions in Broekhuis $(1999,2000)$, it is clear that the movement cannot be triggered by some feature F on V itself - if that were the case, V would also have to move and it should therefore precede the VP-adverb as well (cf. again fn. 11/18). Consequently, there must be some functional head triggering the movement.

The task we are facing now is to identify the functional head that provides a landing site for the direct object, and the feature that triggers the movement. Let us begin with the latter. The assumption that the OV order in Dutch is the result of agreement-driven movement crucially rests on the fact that in, for example, the Romance languages, past participles exhibit gender agreement in certain circumstances. It might therefore be helpful to look for some other feature that may enter into object-verb agreement and that could be the trigger for the movement in (55b). One possible case would be definiteness agreement in languages like Hungarian. The examples in (57) show that the inflection on finite verbs differs depending on the nature of the object: when the object is definite, as in (57a), the verb has the so-called definite conjugation, whereas the verb has the indefinite conjugation when the object is indefinite (see, e.g., Kenesei et al. 1998, pp. 68-70).

$$
\begin{array}{llll}
\text { a. Janos } & \text { szereti } & \text { Mariat. } & \text { (definite conjugation) } \\
\text { John }_{\text {nom }} & \text { loves }_{D E F} & \text { Maria }_{\text {acc }} & \\
\text { b. Janos } & \text { szeret } & \text { egy lanyt. } & \text { (indefinite conjugation) } \\
\text { John nom }_{\text {noves }} & \text { lovDEF }_{\text {IN }} & \text { a girl } &
\end{array}
$$

The data suggest that, apart from the $\Phi$-features, the feature $[ \pm$ definite $]$ may be involved in object-verb agreement. That something like that is the case is also supported by the phenomenon of short object shift. A comparison of the examples in (55) to those in (58) reveals that 'short' object shift is sensitive to the definiteness of the object; indefinite NPs cannot undergo this movement.

(58) a. dat Jan waarschijnlijk morgen/snel een gedicht zal schrijven. that Jan probably tomorrow/quickly a poem will write 'that Jan will probably write a poem tomorrow/quickly.'

b. *dat Jan waarschijnlijk een gedicht morgen/snel zal schrijven.

When we now postulate a functional head $\mathrm{F}$ containing an uninterpretable feature [ + definite], which is situated above $\mathrm{V}$, but below $v$, we can account for the data in (55) and (57) by assuming the constraint DEFINITENESS in (59a). The 
ranking of PROMINENCE, DEFINITENESS, and STAY must be as in (59b): the subranking DEFINITENESS $>$ STAY expresses that definite noun phrases normally move into SpecFP; however, the subranking PROMINENCE $\gg$ DEFINITENESS expresses that this movement is blocked when the object is the prominent part of the focus. Since indefinite noun phrases do not have the feature [ + definite], they cannot be attracted into SpecFP.

a. DEFINITENESS: [+ definite $]$ attracts its goal.

b. Dutch: PROMINENCE $\gg$ DEFINITENESS $>$ STAY

A perhaps not-so-nice property of the constraint DEFINITENESS is that it explicitly refers to a positive value of the definiteness feature. One way to overcome this problem is to assume that the pertinent feature of $\mathrm{F}$ is simply [definite], so that $\mathrm{F}$ can only be present when the clause contains a definite object, that is, a noun phrase containing $\mathrm{D}$, which could be assumed to introduce the interpretable definiteness feature. Another way might be to go to a higher level of abstraction. That this might be the right approach is clear from the fact that 'short' object shift is not only sensitive to PROMINENCE, but also to SCOPE. Consider the examples in (60).

(60) a. Jan heeft waarschijnlijk drie keer twee boeken gekocht (3 times > 2 books)

\section{Jan has probably three time two books bought}

b. Jan heeft waarschijnlijk twee boeken drie keer gekocht (2 books >

The examples in (60a) and (60b) differ in relative scope of the adverb and the direct object. Example (60a) concerns the buying of six different books: (60b), on the other hand, concerns the buying of three copies of two books. Although the noun phrase twee boeken in (60b) is normally referred to as specific, it is certainly not definite. This suggests that the formulation of the constraint involved should be less specific than that of DEFINITENESS in (59a). I leave the proper formulation of the constraint in question to future research.

The remaining question is: What is the functional head F? Of course, we would not like to invent some new functional head, simply for the sake of its specifier position. A reasonable assumption would be that $F$ should be a head that bears some relation to $\mathrm{V}$ - just like I has a temporal relation to $v, \mathrm{~F}$ should bear some semantic relation to $\mathrm{V}$. An option that comes to mind, then, is that $\mathrm{F}$ is the aspectual head Asp. This idea is especially attractive in view of the fact that aspect (or at least, Aktionsart) and definiteness seem to be intimately related. For example, the definiteness of the direct object determines whether a verb like to eat is interpreted as an activity or as an accomplishment. This is illustrated in (61).
a. Jan eet spinazie (activity)
Jan eats spinach
b. Jan eet de spinazie (accomplishment)
Jan eats the spinach 
Adopting this suggestion for the moment, I conclude that short object shift can also be accommodated under the present proposal. The question we have to answer in the future is whether we can identify more landing sites for object/ subject shift (that is, functional heads that contain uninterpretable features that trigger these movements). Given the fact that I and Asp contain features that trigger subject/object shift, a plausible candidate would be the functional head Mood. The extent to which we are able to do this will determine whether we need to introduce additional means to fully describe the relative order of adverbs and arguments.

\section{Conclusion}

Section 3.1 has shown that the constraint ranking in (4) correctly predicts that casedriven movement of the objects and the subject are both sensitive to the information structure of the clause: it is possible only when the object/subject is part of the presupposition of the clause. Section 3.2, on the other hand, showed that the ranking in (4) incorrectly predicts that agreement-driven movement is not only obligatory for objects but also for the subject. It was argued that this problem can be solved by dividing the constraint AGREEMENT into the three constraints AGR PERSON$_{\text {, }}$ $A_{G R}$ NUmber, and $A_{G R}$ GENDER in (42). By assuming that the $\Phi$-feature sets on I and $\mathrm{V}$ differ as in (41), we were able to make the desired distinction. Since the proposal in this article presupposes that object/subject shift is A-movement, Sect. 4 briefly discussed earlier claims that these movements are of the same type as scrambling of PP and showed that these claims cannot be maintained. Section 5 concluded with some speculations on what I called 'short' object shift.

\section{Acknowledgements}

I'd like to thank the three anonymous JCGL reviewers and Susi Wurmbrand for their extensive comments on earlier versions of this paper, which enabled me to improve it in substantial ways. I also want to thank the audiences of the Scrambling workshop organized by the Leiden Center for Linguistics in October 2003, and of the 19th Comparative Germanic Syntax Workshop, organized by the City University of New York in June 2004. This research was funded by the Netherlands Organization for Scientific Research (NWO), grant 276/70-001.

\section{References}

Barbiers, S. (1995). The syntax of interpretation, HIL dissertations 14. PhD dissertation, University of Leiden.

Bennis, H. (1986). Gaps and dummies. Dordrecht: Foris.

Bennis, H., \& Hoekstra, T. (1984). Gaps and parasitic gaps. Linguistic Review, 4, $29-87$.

Bobaljik, J. (2002). A-chains at the PF-interface: Copies and 'covert' movement. Natural Language \& Linguistic Theory, 20, 197-267. 
Bobaljik, J., \& Jonas, D. (1996). Subject positions and the role of TP. Linguistic Inquiry, 27, 195-237. Bobaljik, J., \& Thráinsson, H. (1998). Two heads aren't always better than one. Syntax, 1, 37-71.

Broekhuis, H. (1992). Chain-government: Issues in Dutch syntax. HIL dissertations 2. PhD dissertation, University of Amsterdam/HIL.

Broekhuis, H. (1994). The referential properties of noun phrases. Modern grammar of Dutch occasional papers 1 . University of Tilburg, Models of Grammar.

Broekhuis, H. (1999). Theoretische aspecten van de generatieve syntaxis I-II. Gramma/TTT, 7, 3-23, 89-116.

Broekhuis, H. (2000). Against feature strength: The case of Scandinavian object shift. Natural Language and Linguistic Theory, 18, 673-721.

Broekhuis, H. (in prep). Predicate movement. University of Tilburg.

Broekhuis, H., \& Dekkers, J. (2000). The minimalist program and optimality theory: Derivations and evaluations. In J. Dekkers, F. van der Leeuw, \& J. van de Weijer (Eds.), Optimality theory: Phonology, syntax and acquisition (pp. 386-422). Oxford/New York: Oxford University Press.

Broekhuis, H., Keizer E., \& Den Dikken, M. (2003). Nouns and noun phrases. Modern grammar of Dutch. Occasional papers 4. Tilburg.

Broekhuis, H., \& Klooster, W. (2001). On merge and move/attract. In M. van Oostendorp, \& E. Anagnostopoulou (Eds.), Progress in grammar. Articles at the 20th anniversary of the comparison of grammatical models group in Tilburg. Electronic publication, http:// www.meertens.knaw.nl/books/progressingrammar.

Burzio, L. (1986). Italian syntax: A government-binding approach. Dordrecht: Reidel.

Chomsky, N. (1991). Some notes on economy of derivation and representation. In R. Freidin (Ed.), Principles and parameters in comparative syntax. Cambridge, Mass.: MIT Press.

Chomsky, N. (1995a). Bare phrase structure. In G. Webelhuth (Ed.), Government and binding theory and the minimalist program (pp. 383-439). Oxford/Cambridge, Mass: Blackwell.

Chomsky, N. (1995b). The minimalist program. Cambridge, Mass: MIT Press.

Chomsky, N. (2000). Minimalist inquiries: The framework. In R. Martin, D. Michaels, \& J. Uriagereka (Eds.), Step by step. Essays on minimalist syntax in honor of Howard Lasnik (pp. 89-155). Cambridge, Mass.: MIT Press.

Chomsky, N. (2001). Derivation by phase. In M. Kenstowicz (Ed.), Ken Hale. A life in Language (pp. 1-52). Cambridge, MA: MIT Press.

Chomsky, N. (2004). Beyond explanatory adequacy. In A. Belletti (Ed.), Structures and beyond (pp. 104-131). Oxford: Oxford University Press

Chomsky, N. (2005). On phases, Ms. MIT.

Corver, N., \& Van Riemsdijk, H. (1994). Studies of scrambling: Movement and non-movement approaches to free word-order phenomena. Berlin: Mouton de Gruyter.

Costa, J. (1998). Word order variation. A constraint-based approach. LOT Dissertations 14. $\mathrm{PhD}$.-thesis, University of Leiden

De Hoop, H. (1992). Case configuration and noun phrase interpretation. PhD dissertation, University of Groningen.

De Hoop, H., \& Kosmeijer, W. (1991). Case and scrambling: D-structure vs S-structure, Ms. University of Groningen.

De Hoop, H., \& De Swart, H. (1990). Indefinite objects. In R. Bok-Bennema, \& P. Coopmans (Eds.), Linguistics in the Netherlands 1990 (pp. 91-100). Dordrecht: Foris.

Dekkers, J. (1999). Derivations \& evaluations. On the syntax of subjects and complementizers. Phd.-thesis, HIL dissertations 21.

Den Besten, H. (1985). The ergative hypothesis and free word order in Dutch and German. In J. Toman (Ed.), Studies in German Grammar (pp. 23-65). Dordrecht: Foris.

Den Besten, H., \& Webelhuth, G. (1990). Stranding. In G. Grewendorf, \& W. Sternefeld (Eds.), Scrambling and barriers. Amsterdam: John Benjamins.

Den Besten, H., \& Broekhuis, H. (1992). Verb Projection Raising in the Netherlands. Spektator, 21, 21-34.

Déprez, V., (1989). On the Typology of syntactic positions and the nature of chains: Move-alpha to the specifier of functional projections. PhD.-thesis, MIT.

Diesing, M. (1992). Indefinites. Cambridge, Mass.: MIT Press.

Diesing, M. (1997). Yiddish VP order and the typology of object movement in Germanic. Natural Language and Linguistic Theory, 17, 369-427.

Eisner, J. (1999). Doing OT in a straitjacket. Handout of a talk given at UCLA on 14 June 1999. Available at http://www.cs.jhu.edu/ jason/resume.html\#pubs. 
Emonds, J. E. (1985). A unified theory of syntactic categories. Dordrecht: Foris.

Fox, D., \& Pesetsky D. (2005). Cyclic linearization of syntactic structure. Theoretical Linguistics, 31, $1-46$.

Grimshaw, J. (1997). Projection, heads and optimality. Linguistic Inquiry, 28, 373-422.

Groat, E., \& O'Neil, J. (1996). Spell-Out at the LF interface. In W. Abraham, S. David Epstein, \& H. Thráinsson (Eds.), Minimal ideas. Syntactic studies in the minimalist framework (pp. 113-139). Amsterdam: John Benjamins.

Haeberli, E. (2002). Features, categories and the syntax of A-positions. Dordrecht: Kluwer.

Hoekstra, T., \& Mulder, R. (1990). Unergatives as copular verbs; locational and existential predication. The Linguistic Review, 7, 1-79.

Hornstein, N. (1995). Logical form: From GB to minimalism. Oxford: Blackwell.

Johnson, K. (1991). Object positions. Natural language and Linguistic Theory, 9, 577-636.

Kayne, R. S. (1994). The antisymmetry of syntax. Cambridge, Mass.: MIT Press.

Kayne, R. S. (2000). Parameters and universals. New York: Oxford University Press.

Kenesei, I., Vago, R. M., \& Fenyvesi, A. (1998). Hungarian. London: Routledge.

Koizumi, M. (1993). Object agreement phrases and the split VP hypothesis. In J. Bobaljik, \& C. Phillips (Eds.), Papers on case and agreement I (pp. 99-148). MIT.

Lasnik, H. (1999). Minimalist analysis. Oxford: Blackwell.

Lee, Y.-S., \& Santorini, B. (1994). Towards resolving Webelhuth's paradox: Evidence from German and Korean. In N. Corver, \& H. Van Riemsdijk (Eds.), Studies on Scrambling: Movement and non-movement approaches to free word-order phenomena. Berlin: Mouton de Gruyter.

Longobardi, G. (1994). Reference and proper names: A theory of N-movement in syntax and Logical Form. Linguistic Inquiry, 25, 609-665.

Mahajan, A. (1990). The A/A-bar distinction and movement theory. PhD.-dissertation, MIT.

Milsark, G. (1974). Existential sentences in English. PhD.-dissertation, Massachusetts Institute of Technology.

Molnárfi, L. (2003). On optional movement and feature checking in West Germanic. Folia Linguistica, 28, 129-162.

Müller, G. (2001). Order preservation, parallel movement, and the emergence of the unmarked. In G. Legendre, J. Grimshaw, \& S. Vikner (Eds.), Optimality-theoretic syntax (pp. 113-142). Cambridge Mass: MIT Press/MITWPL.

Nash, L., \& Rouveret, A. (1997). Proxy categories in phrase structure theory. NELS, 27, $287-304$.

Neeleman, A. (1994a). Complex predicates. OTS dissertation series. PhD.-thesis, LEd.

Neeleman, A. (1994b). Scrambling as a D-structure phenomenon, In N. Corver, \& H. Van Riemsdijk (Eds.), Studies on scrambling. Movement and non-movement approaches to free word-order phenomena (pp. 387-429). Berlin: Mouton de Gruyter.

Pesetsky, D. (1998). Some optimality principles of sentence pronunciation. In P. Barbosa, D. Fox, P. Hagstrom, M. McGinnis, \& D. Pesetsky (Eds.), Is the best good enough? (pp. 337-383). Cambridge, Mass.: MIT Press/MITWPL.

Pollock, J.-Y. (1989). Verb movement, Universal Grammar and the structure of IP. Linguistic Inquiry, 20, 365-424.

Vanden Wyngaerd, G. (1988). Raising-to-object in English and Dutch. Dutch Working Papers in English Language and Linguistics, 14.

Vanden Wyngaerd, G. (1989). Object shift as an A-movement rule. MIT Working Papers in Linguistics, 11.

Vikner, S. (1990). Verb movement and licensing of NP positions in the Germanic languages. Dissertation (draft version).

Vikner, S. (1994). Scandinavian object shift and west Germanic scrambling. In N. Corver, \& H. van Riemsdijk (Eds.), Studies on scrambling. Movement and non-movement approaches to free word-order phenomena (pp. 487-517). Berlin: Mouton de Gruyter.

Vogel, R. (2004). Weak function word shift, Ms. University of Potsdam, http://roa.rutgers.edu/files/ 663-0504/663-VOGEL-0-0.PDF.

Webelhuth, G. (1989). Syntactic saturation phenomena and the modern Germanic languages. PhD.dissertation.

Webelhuth, G. (1992). Principles and parameters of syntactic saturation. New York: Oxford University Press.

Zwart, J. W. (1997). Morphosyntax of verb movement. A minimalist approach to the syntax of Dutch. Dordrecht: Kluwer. 